\title{
LINFOMA PERIFÉRICO DE CÉLULAS T SEM OUTRAS ESPECIFICAÇÕES COM ENVOLVIMENTO PAROTÍDEO
}

\author{
PERIPHERAL T-CELL LYMPHOMA, NOT OTHERWISE SPECIFIED, WITH PAROTID INVOLVEMENT
}

Vitorino Modesto dos Santos, Raister Roseake Maia Santos Carvalho, Camila Azevedo Silva, Kamila Fernandes Ferreira, Layssa Melo Feitosa

DOI - 10.5935/2236-5117.2018v55a09

\section{RESUMO}

O linfoma periférico de células $\mathrm{T}$ sem outras especificações (PTCL-NOS) pertence a uma categoria heterogênea de linfomas de células T maduras, nodais e extranodais, e não se enquadram em outras modalidades dessa malignidade. São mais frequentes em homens com idade aproximada de 60 anos. No ocidente, podem corresponder a até 35\% desses linfomas. Tem curso usualmente agressivo com tendência a acometimento sistêmico e mau prognóstico. Imunossupressão, viroses (Epstein-Barr), tabagismo, e agentes químicos são fatores de risco. O diagnóstico de certeza depende de exame histopatológico e imunoistoquímico de linfonodo. Descreve-se o caso de PTCL-NOS com acometimento parotídeo em um homem de 22 anos.

Palavras-chave: Linfoma periférico de células T; parótida; síndrome de lise tumoral.

\section{ABSTRACT}

Peripheral T-cell lymphoma without other specifications (PTCL-NOS) belongs to a heterogeneous category of mature, nodal and extranodal T-cell lymphomas, and does not fit into other modalities of this malignancy. It occurs mainly in men and around the age of 60. The Occident may account for up to $35 \%$ of PTCL-NOS. It has a usually aggressive course with a tendency to systemic involvement and poor prognosis. Immunosuppression, viruses (Epstein-Barr), smoking, and chemical agents are risk factors. The diagnostic confirmation depends on the histopathological and immunohistochemical evaluation of lymph nodes. A case of PTCL-NOS with parotid involvement in a 22-year-old man is described.

Keywords: Peripheral T-cell lymphoma; parotid gland; tumor lysis syndrome.
Vitorino Modesto dos Santos - Santos VM. Médico. Docente do Curso de Graduação em Medicina da Universidade Católica de Brasília (UCB), Brasília, Distrito Federal, Brasil, e Unidade de Clínica Médica do Hospital das Forças Armadas (HFA), Brasília, Distrito Federal, Brasil.

Raister Roseake Maia Santos Carvalho - Carvalho RRMS. Médica residente de Clínica Médica do Hospital das Forças Armadas, Brasilia, Distrito Federal, Brasil.

Camila Azevedo Silva - Silva CA. Médica residente de Clínica Médica do Hospital das Forças Armadas, Brasilia, Distrito Federal, Brasil.

Kamila Fernandes Ferreira - Ferreira KF. Médica residente de Clínica Médica do Hospital das Forças Armadas, Brasília, Distrito Federal, Brasil.

Layssa Melo Feitosa - Feitosa LM. Médica residente de Clínica Médica do Hospital das Forças Armadas, Brasília, Distrito Federal, Brasil.

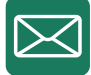

Correspondência: Vitorino Modesto dos Santos. Hospital das Forças Armadas. Estrada do Contorno do Bosque s/n, Cruzeiro Novo, CEP 70.658-900, Brasília-DF, Brasil.

Internet: vitorinomodesto@gmail.com

Telefone: +556139662103

Conflito de interesses: não existem conflitos de interesse.

\section{INTRODUÇÃO}

O linfoma periférico de células $T$ sem outras especificações (PTCL-NOS) pertence a uma classe heterogênea de linfomas de células $T$ maduras, nodais e extranodais, que não se classificam em outras modalidades dessa condição maligna. ${ }^{1-11}$ Acometem homens com maior frequência $(2,5: 1)$ e são responsáveis por 10 a $35 \%$ de todos os casos de PTCL nos países ocidentais. ${ }^{1-6,8,9}$ São condições agressivas que comumente ocorrem em torno dos 60 anos de idade. $2,3,5,6,9$ Até aproximadamente $70 \%$ dos casos já estão avançados na ocasião do diagnóstico. 2,8 Imunossupressão, infecção por vírus Epstein-Barr, fumo e agentes químicos são fatores de risco. ${ }^{5,6,8,9,12}$ Febre, perda de peso, esplenomegalia e alterações cutâneas são comuns6. Sítios extranodais frequentes são a medula óssea $(21 \%)$, a pele $(16 \%)$, o fígado $(12 \%)$ e o baço. ${ }^{1,2,6,8,9} \mathrm{~A}$ rotina laboratorial usualmente revela anemia, trombocitose, linfocitose, eosinofilia, 
hipergamaglobulinemia, e níveis séricos elevados de desidrogenase lática. 4-6,8,9,11 Exames histopatológicos de biópsias em linfonodos são necessários para o diagnóstico. ${ }^{2-6,9,11} \mathrm{O}$ imunofenótipo clássico de PTCLNOS usualmente revela CD3+, CD5+, CD7+, CD99+, CD4-, CD8-, CD30-, CD56-, TdT-, CD1a-, CD34-, CD10, e Ki67+. ${ }^{2,5,6,8,8,9,11} \mathrm{Na}$ avaliação, devem ser incluídas sorologias (vírus da imunodeficiência humana - HIV, vírus T-linfotrópico humano - HTLV, e vírus das hepatites $\mathrm{B}$ e C), tomografia computadorizada (TC) de pescoço, tórax, abdome e pelve, e tomografia computadorizada por emissão de pósitrons (PET-TC), sendo o valor padronizado de captação (SUV, do inglês standardized uptake value) médio de $12,3(2,8$ a 42,3).46,9 A sobrevida em cinco e dez anos pode alcançar até $50 \%$ e $20 \%$, respectivamente. . $^{2,8-10}$ Casos refratários ao tratamento adequado ou que apresentam recorrências têm pior prognóstico, especialmente se ocorrer infiltração do sistema nervoso central. ${ }^{2-4,10}$

No presente caso, descreve-se um paciente jovem portador de PTCL-NOS com apresentação extranodal, incluindo a parótida esquerda. Dados da biópsia de pele foram compatíveis com PTCL-NOS, diagnóstico depois confirmado por exame imunoistoquímico de amostra da glândula salivar afetada. O tratamento incluiu ciclofosfamida, doxorrubicina, vincristina e prednisona (CHOP), opção considerada de primeira linha para PTCL-NOS. ${ }^{2-7,10}$ Antes da quimioterapia, 0 paciente apresentou síndrome de lise tumoral (SLT) espontânea13.

\section{RELATO DE CASO}

Homem pardo de 22 anos, previamente hígido, foi admitido no Hospital das Forças Armadas, Brasil, para esclarecimento diagnóstico de febre noturna $\left(38-39^{\circ} \mathrm{C}\right)$ diária há uma semana, associada a acentuado aumento de região cervical esquerda, astenia, hiporexia, vômitos e dor abdominal. Dois meses antes da internação, notou nódulo eritematoso indolor no couro cabeludo e alopecia local, além de desenvolvimento rápido de nódulos próximos com tamanho variado. Ao exame físico, apresentava índice de massa corpórea (IMC) de $30,81 \mathrm{~kg} / \mathrm{m}^{2}$ e havia linfonodomegalia bilateral: submandibulares $(1,0$ $\mathrm{cm})$, cervicais anteriores, retro auriculares, e cervical posterior à direita, além de nódulos eritematosos indolores no couro cabeludo com áreas de alopecia no local (figura1). 0 restante do exame foi inexpressivo, com ausência de hepatomegalia ou esplenomegalia. Os exames laboratoriais alterados foram: hemograma com 1,06 x 109 leucócitos $/ \mathrm{mm}^{3}$ (valor normal: 4 a 10 x 109 leucócitos $/ \mathrm{mm}^{3}$ ), VHS: $33 \mathrm{~mm} / 1 \mathrm{~h}$ (valor normal $<15 \mathrm{~mm} / 1 \mathrm{~h}$ ), ureia: $72,8 \mathrm{mg} / \mathrm{dL}$ (valor normal 10 a 50 $\mathrm{mg} / \mathrm{dL}$ ), creatinina: $2,9 \mathrm{mg} / \mathrm{dL}$ (valor normal: 0,7 a 1,3 $\mathrm{mg} / \mathrm{dL}$ ), ácido úrico: $12,6 \mathrm{mg} / \mathrm{dL}$ (valor normal 3,4 a
7,0 mg/dL), desidrogenase lática: 1060,4 UI/L (valor normal: <250,0 UI/L), e fósforo: $5,2 \mathrm{mg} / \mathrm{dL}$ (valor normal: 2,7 a $4,5 \mathrm{mg} / \mathrm{dL}$ ). Não foram relevantes os resultados dos testes sorológicos para hepatites $A$, B e C, HIV-1 e HIV-2, Citomegalovírus, Epstein-Barr vírus, Toxoplasma gondii, e Treponema pallidum.

No primeiro dia, as TCs com contraste de pescoço, tórax e abdome mostraram numerosos linfonodos cervicais (aumentados bilateralmente e sem configurar linfonodomegalia), glândula parótida esquerda hiperatenuante e hipertrofiada, seios maxilares com espessamento nodular, linfonodomegalias com aspecto de lesão expansiva no mediastino anterior, discreta esplenomegalia, aumento numérico de linfonodos em cadeias aórtica, pré-aórtica, celíaca e ilíaca interna, rins hipertrofiados com perda de diferenciação córticomedular, e lesões infiltrativas bilaterais.

Foi admitido para investigação das hipóteses de doença linfoproliferativa e SLT espontânea, além de neutropenia febril. Fez uso de levofloxacino (por sete dias) e prednisona $100 \mathrm{mg} /$ dia (por cinco dias), com melhora clínica. Depois da antibioticoterapia, houve recorrência da febre com taquicardia persistente e piora progressiva da função renal, mesmo com a administração de alopurinol e hidratação vigorosa com objetivo de controlar a SLT. Foi, então, admitido em unidade de terapia intensiva, sendo iniciado cefepime. Houve expectativa a respeito de eventual indicação de terapia renal substitutiva no décimo quinto dia, ocasião em que os exames de controle mostraram hemograma com 4.105 leucócitos $/ \mathrm{mm}^{3}$ e $10 \%$ de bastões, ureia: $97,6 \mathrm{md} / \mathrm{dL}$, creatinina: 5,6 mg/dL, acidose metabólica, e eletrólitos na faixa de normalidade.

Imagens de PET-CT (figura 2) mostraram pólipos ou cistos de retenção em seios maxilares, aumento do metabolismo nas glândulas submandibulares e na parótida esquerda (SUV de 7,4), enfisema subcutâneo no sítio de biópsia na parótida esquerda, linfonodopatias hipermetabólicas bilaterais préparotídeas e nos níveis IIA, IIB, III, IV, V e VI, medindo até $20 \mathrm{~mm}$ no maior diâmetro (SUV de $5,2)$, linfonodomegalias hipermetabólicas formando massa no mediastino anterior com $128 \mathrm{~mm}$ no maior diâmetro (bulky disease) (SUV de 13,8), linfonodo paratraqueal inferior direito sem hipermetabolismo (12 mm no maior diâmetro). No abdome, havia linfonodomegalia hipermetabólica na cabeça do pâncreas (51 mm no maior diâmetro e SUV de 6,1), rins hipertrofiados com perda da relação córticomedular e hipermetabolismo (SUV de 11,4). Foram observadas ainda áreas hipermetabólicas na pele e subcutâneo da face, orelhas e couro cabeludo (SUV de 9,7), hipermetabolismo na medula óssea e foco de maior intensidade no corpo vertebral de T6 (SUV 
de 6,7), captação mediastinal (SUV de 2,9) e hepática (SUV de 2,7). Ressonância nuclear magnética (RNM) de crânio com contraste mostrou meninges com realce difuso e nódulos sem realce no couro cabeludo, estando o parênquima cerebral com aspecto normal.

A pesquisa de células oncóticas realizada no líquor teve resultado negativo. Estudo histopatológico de amostra do couro cabeludo foi inconclusivo, mas a imunoistoquímica revelou infiltrado denso de células mononucleares com imunofenótipo T (CD3+, CD5+,
TdT- e CD34-) e um alto índice de proliferação celular, consistentes com linfoma de células T. Biópsias de linfonodo e de parótida (figura 3) confirmaram o PTCL-NOS (CD3+, CD5+, CD7+, CD99+, CD4-, CD8-, CD30-, CD56-, TdT-, CD1a-, CD34-, CD10-, Ki67+:80 a $90 \%$. Então, o paciente iniciou tratamento com protocolo CHOP que resultou em redução das lesões no couro cabeludo e da linfonodomegalia cervical esquerda, e normalização da função renal. Recebeu alta assintomático no vigésimo dia e foi encaminhado para o ambulatório de hematologia.

Figura 1. Aspecto dos nódulos no couro cabeludo associados com áreas de alopecia

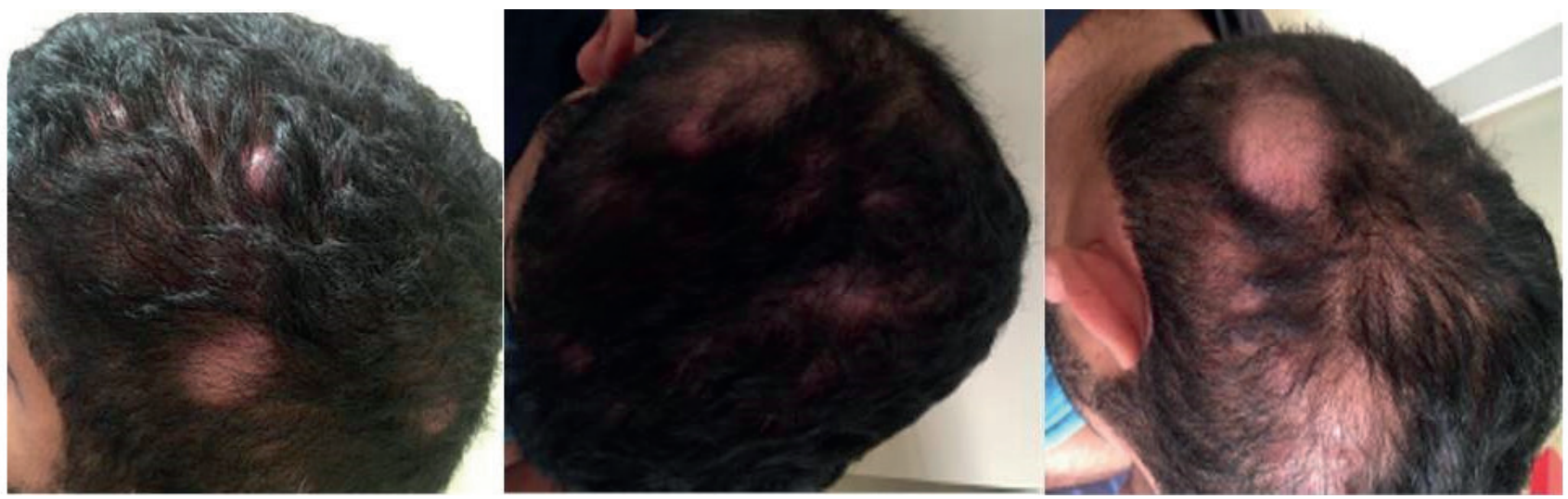

Figura 2. Imagens de PET CT revelando espessamento em seios maxilares; aumento do metabolismo nas glândulas submandibulares e na parótida esquerda; linfonodos hipermetabólicos pré-parotídeos bilaterais, na cabeça do pâncreas, e formando bulky disease no mediastino anterior; áreas hipermetabólicas na pele e no subcutâneo da face, orelhas e couro cabeludo; hipermetabolismo na medula óssea, no mediastino, nos rins e no fígado.

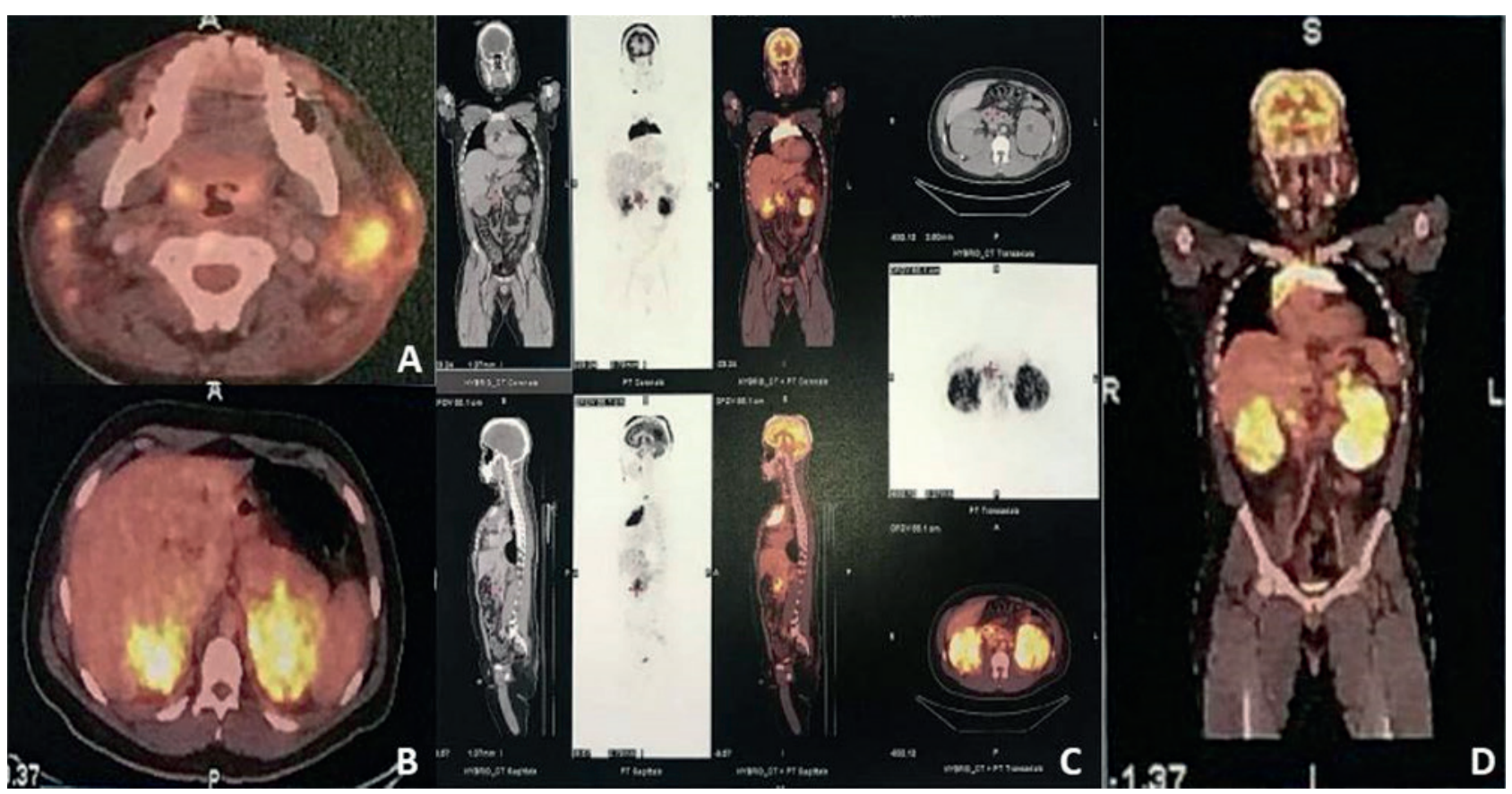


Figura 3. A (HE, grande aumento): infiltrado de linfócitos atípicos na parótida; B a D (Imuno-histoquímica): expressão de CD3, CD5, e CD7 em células neoplásicas na parótida.

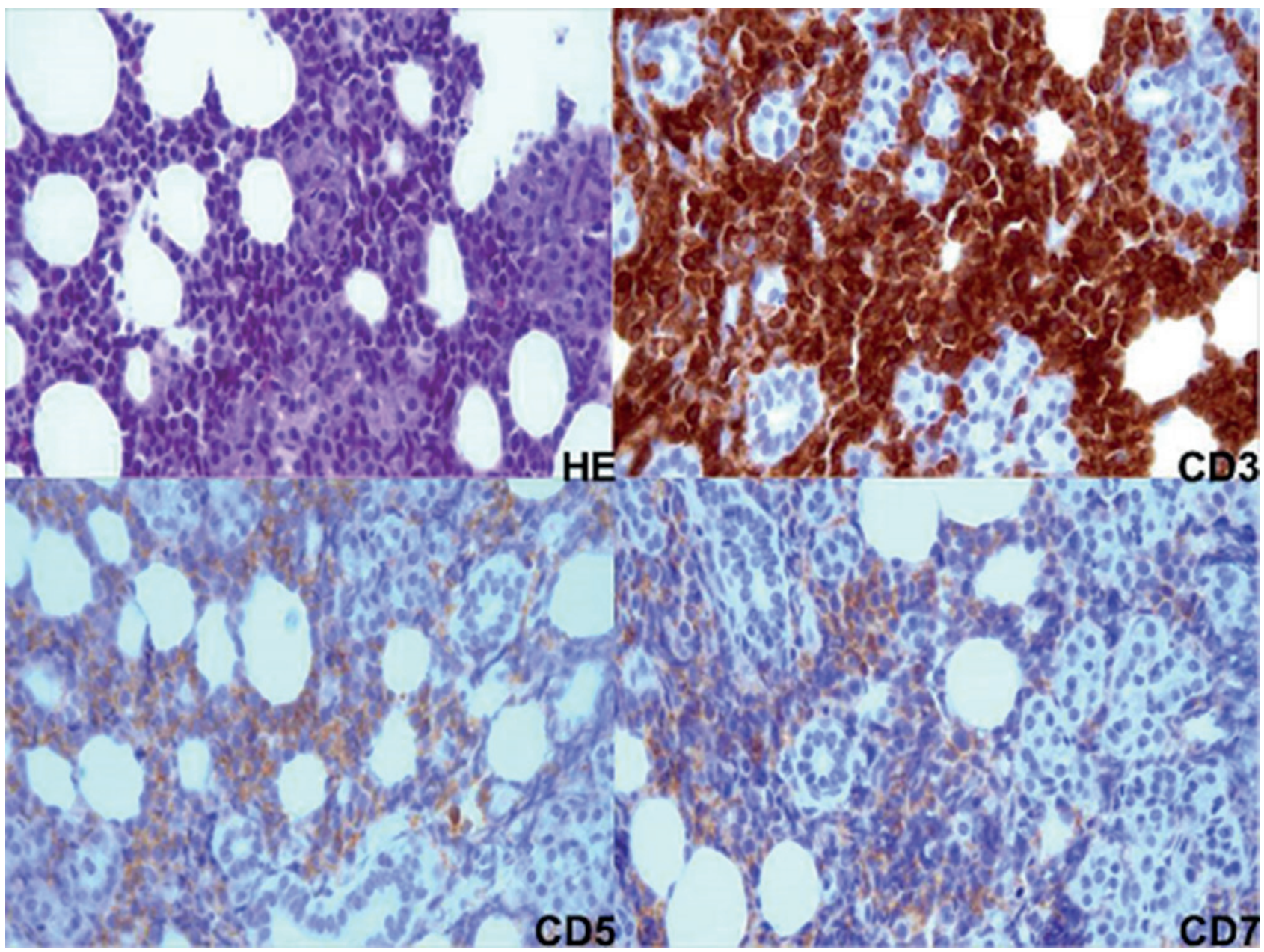

\section{DISCUSSÃO}

Diferente do que consta na maioria dos casos descritos na literatura, as manifestações de PTCLNOS aqui relatadas iniciaram em um homem hígido e com 22 anos de idade. 2,3,5,6,9 Já, o quadro clínico inicial que incluiu febre elevada, astenia, hiporexia, dor abdominal, vômitos e linfadenopatias, correspondeu ao que classicamente se descreve nesses linfomas6. 0 paciente apresentou aumento de linfonodos cervicais, submandibulares, retro-auriculares, mediastinais, e nas cadeias pré-aórtica, aórtica, e ilíaca interna.

Foram sítios extranodais o ouro cabeludo (nódulos)8, seio paranasal (espessamento), ${ }^{4}$ e glândula salivar (parótida). ${ }^{14,15} \mathrm{O}$ envolvimento do sistema nervoso central foi descartado por imagens e citologia do líquor. ${ }^{4}$ Em conjunto, os dados preliminares mimetizaram uma infecção ativa por Epstein-Barr vírus, condição que pode até mesmo ocorrer concomitante ao desenvolvimento de PTCL-NOS. ${ }^{12}$ Porém, essa hipótese foi afastada por resultados negativos de testes sorológicos específicos. Dermatoses nodulares, doenças tropicais, leucemias, e outros linfomas foram possibilidades também descartadas com o estudo histopatológico e a avaliação imunoistoquímica. ${ }^{2-6,9,11}$

Aventou-se a possibilidade diagnóstica de SLT com base no conjunto de alterações semelhantes às que são classicamente descritas 48 a 72 horas após início de quimioterapias. ${ }^{13} \mathrm{~A}$ presença de dois critérios clínicos (lesão renal aguda e arritmia cardíaca) e variações em exames de laboratório confirmaram a SLT: ureia de 132,0 para $72,8 \mathrm{mg} / \mathrm{dL}$, creatinina de 5,6 para $2,9 \mathrm{mg} /$ $\mathrm{dL}$, cálcio não-ionizado de 1,31 para 1,08 mmol/L (valor normal: 1,12 a 1,32 mmol/L), fósforo de 9,4 para 5,2 $\mathrm{mg} / \mathrm{dL}$ (valor normal: 2,7 a 4,5 mg/dL), e ácido úrico de 12,6 para $4,2 \mathrm{mg} / \mathrm{dL}$ (valor normal: 3,4 a 7,0 mg/dL). ${ }^{13}$ 
Podem ser destacados quatro itens desse caso: a idade do jovem com PTCL-NOS, a semelhança com infecção por Epstein-Barr vírus, a SLT, e o envolvimento da parótida. ${ }^{11-15}$ Linfomas deglândulas salivares representam aproximadamente $5 \%$ das sedes extranodais da doença, até $2 \%$ das neoplasias nesse sítio, e 10\% dos tumores malignos de glândula salivar. ${ }^{14}$ Pai et al. descreveram um homem de 26 anos apresentando placas e pápulas eritematosas disseminadas e com áreas de atrofia e alopecia local desde os 18 anos de idade. ${ }^{8}$ Os achados histopatológicos e imunoistoquímicos confirmaram tratar-se de PTCL-NOS, que é incomum nessa faixa etária, semelhanteao ocorrido no estudo de caso descrito. Porém, os autores enfatizaram a ausência de linfonodomegalias ou invasão em outros sítios8. Wollina et al. relataram placas e nódulos cutâneos na cabeça e no pescoço de um homem com 53 anos portador de PTCL-NOS, cujo diagnóstico foi confirmado por imunoistoquímica. ${ }^{11}$ 0 esquema de tratamento utilizado foi rituximabe, ciclofosfamida, doxorrubicina, vincristina e prednisona. ${ }^{11}$ Os autores salientaram a ausência de linfadenopatias e de disseminação do linfoma para outros órgãos. Porém, o aumento de volume da parótida foi identificado como adenoma, embora os dados histopatológicos da glândula não tenham sido comentados. ${ }^{11}$ No presente caso, os achados imunoistoquímicos confirmaram o PTCL-NOS na parótida.

Zhang et al. relataram o caso de um homem com 25 anos e infecção aguda por Epstein-Barr vírus, que mimetizou PTCL-NOS clinicamente, nos achados histopatológicos e na imunofenotipagem (CD2+, CD3+, CD8+, TIA-1+, CD5-, CD7-, CD30-, CD56-, ALK1-, e TdT-). Os autores comentaram o importante papel dessa virose na proliferação de linfócitos T CD8+ e sua associação com condições benignas e malignas em pacientes jovens, incluindo PTCLs. ${ }^{12}$

Belay et al. enfatizaram a rara ocorrência e maior gravidade da SLT espontânea em pacientes com malignidades hematológicas, como se pode constatar na evolução do paciente relatado. ${ }^{13}$ De fato, foram confirmadas mais de três alterações que constam dos critérios diagnósticos; ${ }^{13}$ e os distúrbios renais e cardíacos, colocaram em risco a vida do paciente. Os níveis normais de potássio, pelo menos em parte poderiam ser justificados por se tratar de jovem com baixo risco para SLT e uma boa resposta ao tratamento, sem acentuada oligúria. ${ }^{13}$ Soro glicosado hipertônico, insulina, diurético de alça e bicarbonato constam do esquema. ${ }^{13}$ Gorodetskiy et al. descreveram leucemia linfocítica crônica (LLC)/linfoma linfocítico de pequenas células (LLPC) em um homem de 38 anos, previamente saudável, que apresentou aumento rápido de linfonodos supraclaviculares esquerdos, axilares, inguinais, hilares, mediastinais, abdominais, retroperitoniais, retrocrurais e ilíacos, e hepatoesplenomegalia. ${ }^{14}$

Além disso, houve o crescimento de uma massa indolor na região da glândula submandibular esquerda, bem como elevação no nível de desidrogenase lática, ${ }^{14}$ fenômenos muito semelhantes ao que se observou no presente estudo de caso. A biopsia da glândula salivar revelou duas populações de linfócitos; uns típicos de LLC/ LLPC, outros de PTCL-NOS (pequenos linfócitos com fenótipo citotóxico e expressando CD79a)..$^{14}$ A maioria das células era CD2+, CD3+, $\mathrm{CD} 5+, \mathrm{CD} 7+, \mathrm{CD} 8+, \mathrm{CD} 43+, \mathrm{TIA} 1+; 70 \% \mathrm{Ki}-67+.^{14}$ Os autores fizeram uma revisão e encontraram somente 16 casos de linfoma com sede em glândulas salivares: nove em parótidas, cinco em submandibulares, e dois em sublinguais. ${ }^{14}$ Os típicos linfomas primários de glândula salivar não apresentam cápsula de linfonodo nem seu resquício, que poderiam indicar que os infiltrados seriam secundários a linfonodo local.14 Öneç et al. relataram o caso de um homem de 63 anos com uma massa medindo 47 x $39 \mathrm{~mm}$ na parótida esquerda e envolvimento da orelha e de linfonodos subauriculares e cervicais. ${ }^{15}$ Dados de biópsia estabeleceram o diagnóstico de PTCL-NOS.

O controle do tratamento inicial, após o quarto ciclo com CHOP, revelou progressão da doença. 0 esquema de segunda linha DHAP (dexametasona, alta dose de citarabina e cisplatina) foi utilizado com sucesso. ${ }^{15}$ Os autores comentaram a extrema raridade de linfomas de células T primários em glândulas salivares e o papel da biopsia para o diagnóstico precoce e início do tratamento adequado. ${ }^{15}$

\section{CONCLUSÃO}

O linfoma periférico de células $T$ sem outras especificações com manifestação extranodal em indivíduo jovem é uma condição considerada incomum que pode evoluir sem diagnóstico, ou ser pouco descrita na literatura. Infiltração de glândula salivar é rara, mas deve ser excluída por estudo de biópsia. O linfoma detectado na parótida do paciente não disseminou de linfonodos intraglandulares. Recursos sofisticados de alto custo são usados para confirmar o diagnóstico, o que pode dificultar o manuseio de pacientes em áreas de baixa renda. A síndrome de lise tumoral é outro desafio. 0 presente relato mostra dificuldades que profissionais de saúde podem enfrentar. 


\section{REFERÊNCIAS}

1. Swerdlow $\mathrm{SH}$, Campo E, Harris NL, Jaffe ES, Pileri $\mathrm{SA}$, Stein $\mathrm{H}$ et al. WHO classification of tumours of haematopoietic and lymphoid tissues. Lyon: International Agency for Research on Cancer / World Health Organization; 2017.

2. Beaven AW, Diehl LF. Peripheral T-cell lymphoma, NOS, and anaplastic large cell lymphoma. Hematology Am Soc Hematol Educ Program. 2015;2015:550-8.

3. Bellei M, Foss FM, Shustov AR, Horwitz SM, Marcheselli L, Kim WS et al. The outcome of peripheral T-cell lymphoma patients failing first line therapy: a report from the prospective, international T-Cell project. Haematologica. 2018;103(7):11917.

4. Chihara D, Fanale MA, Miranda RN, Noorani M, Westin JR, Nastoupil LJ et al. The risk of central nervous system relapses in patients with peripheral T-cell lymphoma. PLoS One. 2018;13(3):e0191461.

5. d'Amore F, Gaulard P, Trumper L, Corradini P, Kim WS, Specht $L$ et al. Peripheral T-cell lymphomas: ESMO Clinical Practice Guidelines for diagnosis, treatment and follow-up. Ann Oncol. 2015;26(Suppl 5):v10815.

6. Jha KK, Gupta SK, Saluja H, Subedi N. Peripheral T-cell lymphoma, not otherwise specified. J Family Med Prim Care. 2017;6(2):427-430.

7. Jia B, Hu S, Yang J, Zhou S, Liu P, Qin $Y$ et al. Comparison of gemcitabin, cisplatin, and dexamethasone (GDP), CHOP, and CHOPE in the first-line treatment of peripheral T-cell lymphomas. Hematology. 2016;21(9):536-41.

8. Pai AH, George A, Adiga D, Girisha BS. Peripheral T cell lymphoma: not otherwise specified. Indian J Dermatol. 2015;60(2):215.

9. Park HS, Mclntosh $L$, Braschi-Amirfarzan $M$, Shinagare AB, Krajewski KM. T-cell non-Hodgkin lymphomas: spectrum of disease and the role of imaging in the management of common subtypes. Korean J Radiol. 2017;18(1):71-83.

10. Schmitz N, de Leval L. How I manage peripheral T-cell lymphoma not otherwise specified and angioimmunoblastic T-cell lymphoma: current practice and a glimpse into de future. Brit J Haematol. 2016;176(6):851-66.

11. Wollina U, Hansel G, Langner D, Koch A, Schönlebe J, Tchernev G. Rapid evolving unilateral indurated oozing facial plaques in a patient with head-andneck cancer: peripheral T-cell lymphoma not otherwise specified (NOS). Open Access Maced J 